\title{
Measurements of stress and fracture in germanium electrodes of lithium-ion batteries during electrochemical lithiation and delithiation
}

\author{
Matt Pharr, ${ }^{a}$ Yong Seok Choi, ${ }^{a, b}$ Dongwoo Lee, ${ }^{a}$ Kyu Hwan Oh, ${ }^{b}$ Joost J. Vlassak ${ }^{a,}{ }^{\star}$ \\ a School of Engineering and Applied Sciences, Harvard University, Cambridge, \\ Massachusetts, 02138, USA \\ ${ }^{\mathrm{b}}$ Department of Materials Science and Engineering, Seoul National University, Seoul, \\ 151-742, Korea \\ *Corresponding author. E-mail address: vlassak@seas.harvard.edu (J.J. Vlassak)
}

\begin{abstract}
We measure stresses that develop in sputter-deposited amorphous Ge thin films during electrochemical lithiation and delithiation. Amorphous $\mathrm{Li}_{x} \mathrm{Ge}$ electrodes are found to flow plastically at stresses that are significantly smaller than those of their amorphous $\mathrm{Li}_{x} \mathrm{Si}$ counterparts. The stress measurements allow for quantification of the elastic modulus of amorphous $\mathrm{Li}_{\mathrm{x}} \mathrm{Ge}$ as a function of lithium concentration, indicating a much-reduced stiffness compared to pure Ge. Additionally, we observe that thinner films of Ge survive a cycle of lithiation and delithiation, whereas thicker films fracture. By monitoring the critical conditions for crack formation, the fracture energy is calculated using an analysis from fracture mechanics. The fracture energies are determined to be $\Gamma=8.0 \mathrm{~J} \mathrm{~m}^{-2}$ for a- $\mathrm{Li}_{0.3} \mathrm{Ge}$ and $\Gamma=5.6 \mathrm{~J} \mathrm{~m}^{-2}$ for a- $\mathrm{Li}_{1.6} \mathrm{Ge}$. These values are similar to the fracture energy of pure Ge and are typical for brittle fracture. Despite being brittle, the ability of amorphous $\mathrm{Li}_{x} \mathrm{Ge}$ to flow at relatively small stresses during lithiation results in an enhanced ability of Ge electrodes to endure electrochemical cycling without fracture.
\end{abstract}




\section{Introduction}

Lithium ion batteries provide power for an increasing number of applications, particularly in portable electronic devices and electric vehicles [1-4]. On the anode side, silicon has received much attention due to its extremely high specific capacity ( 3579 $\mathrm{mAh}^{-1}$ ) [5], which is almost ten times larger than that of the commercial anode of choice, graphite $\left(\sim 372 \mathrm{mAh} \mathrm{g}^{-1}\right)$ [5-8]. However, lithiation of silicon causes an enormous increase in volume of $\sim 280 \%$, which can result in large stresses and fracture under constraint [9-45]. Fracture leads to loss of active material and creates more surface area for solid-electrolyte interphase (SEI) growth, both of which substantially contribute to capacity fade in the system [9-13]. This mechanical degradation has been mitigated to varying degrees of success via nano-structuring of the electrodes, but it remains an important issue in constructing practical silicon anodes [14-24]. Germanium, another group IV element, has garnered relatively little attention as an anode material despite its comparatively large theoretical charge density: $\sim 7370 \mathrm{mAh} \mathrm{cm}{ }^{-3}$ for $\mathrm{Li}_{15} \mathrm{Ge}_{4}$ versus $\sim 8330 \mathrm{mAh} \mathrm{cm}^{-3}$ for $\mathrm{Li}_{15} \mathrm{Si}_{4}$ [46]. Furthermore, both the electronic conductivity of $\mathrm{Ge}$ and the diffusivity of Li within Ge have been reported to be much larger than those of $\mathrm{Si}$, thereby making Ge a promising candidate for high-rate applications (e.g., high-power applications) [14, 47]. Still, prior to implementation of $\mathrm{Ge}$ as a practical anode material, it is important to evaluate its mechanical performance during electrochemical cycling.

To date, relatively few studies have examined mechanical characteristics of germanium anodes. Using in-situ transmission electron microscopy in Ge nanowires, Liu et al. found the volumetric expansion upon lithiation to be nearly isotropic and highly reversible upon delithiation [48]. Liang et al. also found highly reversible isotropic 
swelling and de-swelling of crystalline Ge nanoparticles upon lithiation and delithiation [49]. Moreover, they observed no fracture, even during multiple cycles, for particles with an initial diameter as large as $620 \mathrm{~nm}$ [49]. This resistance to fracture was attributed to the isotropic nature of lithiation [49], which is in stark contrast to the highly anisotropic lithiation observed in crystalline silicon electrodes $[9,10,25,26]$. The anisotropic lithiation of c-Si leads to stress concentrations, thereby increasing the driving force for fracture relative to the isotropic (e.g., Ge) case. Lee et al. found a critical pillar diameter of 1.2 $\mu \mathrm{m}$ for fracture of $<111>$ axially oriented Ge nano-pillars [50]. They also attributed this larger critical size than that of Si nano-pillars $(\sim 300 \mathrm{~nm})$ to the nearly isotropic lithiation of Ge [50]. Overall, these studies suggest improved mechanical robustness of crystalline Ge electrodes compared to their crystalline Si counterparts. However, studies aimed at experimental quantification of mechanical properties of $L_{x} G e$ are lacking. In particular, measurements of quantities such as the elastic modulus, the fracture energy, and the stresses that develop during electrochemical cycling are essential for enabling practical designs of Ge electrodes that avoid mechanical degradation.

In this study, we have performed mechanical measurements of a-Lix $\mathrm{Ge}$ electrodes in-situ during electrochemical cycling. In particular, we have measured the stresses that develop during lithiation and delithiation as a function of lithium concentration. The a-Lix Ge electrodes were observed to flow plastically and develop smaller stresses than their a-Lix $\mathrm{Si}$ counterparts. These in-situ stress measurements also allowed for quantification of the elastic modulus of a-Li $\mathrm{i}_{x} \mathrm{Ge}$. Furthermore, we observed that thinner films of germanium survive a cycle of lithiation and delithiation, whereas thicker films fracture. The fracture energy was calculated based on the critical 
conditions for crack formation using an analysis from fracture mechanics. Overall, these measurements indicate an enhanced ability of Ge electrodes to endure electrochemical cycling without fracture relative to their silicon counterparts.

\section{Experimental Procedures}

Glass substrates with a thickness of $1 \mathrm{~mm}$ were cleaned with acetone and isopropanol, and placed into a sputter deposition system (AJA Int. ATC 1800) with a base pressure of $<10^{-8}$ Torr . All depositions were performed at room temperature $\left(22^{\circ} \mathrm{C}\right)$, using sputtering targets with a $50.8 \mathrm{~mm}$ diameter. First, the substrates were plasma-cleaned in Ar at 20 mTorr using an RF power of $24 \mathrm{~W}$ for 5 minutes. Next, $15 \mathrm{~nm}$ of Ti was sputtered onto the substrates using a pressure of $3 \mathrm{mTorr}$ of $\mathrm{Ar}$ and a DC power of $100 \mathrm{~W}$ for 5 minutes. A $300 \mathrm{~nm}$ layer of $\mathrm{Cu}$ was then deposited using a pressure of $5 \mathrm{mTorr}$ of $\mathrm{Ar}$ and a DC power of $100 \mathrm{~W}$ for 15 minutes. The Cu film served as current collector, while the Ti under-layer was used to improve the adhesion between the $\mathrm{Cu}$ film and the glass substrate. Finally, films of Ge with varying thickness were deposited using a pressure of $5 \mathrm{mTorr}$ of $\mathrm{Ar}$ and a DC power of $100 \mathrm{~W}$. The working area of each Ge electrode was $8 \mathrm{~mm}$ by $30 \mathrm{~mm}$.

Electrochemical cells were assembled in a glove box maintained at a moisture level of less than $1 \mathrm{ppm}$, using a $1 \mathrm{M}$ solution of $\mathrm{LiPF}_{6}$ in 1:1:1 (weight \%) ethylene carbonate : diethyl carbonate : dimethyl carbonate as the electrolyte. Electrochemical measurements were performed with a VersaSTAT 3 galvanostat from Princeton Applied Research. The electrodes were lithiated at a $\mathrm{C} / 16$ rate (assuming a specific capacity of 
$1384 \mathrm{mAh} \mathrm{g}^{-1}$ for $\mathrm{Li}_{15} \mathrm{Ge}_{4}$ and a density of pure $\mathrm{Ge}$ of $\left.5.32 \mathrm{~g} \mathrm{~cm}^{-3}[51,52]\right)$ to a cutoff voltage of $50 \mathrm{mV}$. Delithiation was performed at the same rate to a cutoff voltage of $2 \mathrm{~V}$.

Stresses in the Ge films were measured by monitoring the curvature of the substrate during lithiation and delithiation. The stresses in the films were calculated using Stoney's equation [53, 54],

$$
\sigma=\sigma_{r}+\frac{E_{s} h_{s}^{2}}{6 h_{f}\left(1-v_{s}\right)} \Delta K
$$

where $\sigma$ represents the average stress in the film, $\sigma_{r}$ is the residual stress in the asdeposited Ge film, $E_{s}$ is the elastic modulus of the substrate, $h_{s}$ is the thickness of the substrate, $v_{s}$ is Poisson's ratio of the substrate, and $\Delta K$ is the change in curvature of the substrate induced by changes in the stress in the film. The residual stress in the asdeposited Ge film was determined by measuring the curvature of the glass substrate before and after Ge deposition. In the calculations, values of $E_{s}=72 \mathrm{GPa}$ and $v_{s}=0.23$ were used for the glass substrate [55].

The change in curvature of the substrate was monitored with a multi-beam optical sensor (MOS) from k-Space Associates. For more details on this method, please see Reference [29]. The change in the curvature of the substrate was calculated from the geometric relation,

$$
\Delta K=\frac{d_{0}-d}{d_{0}}\left[\frac{\cos \alpha}{2 L}\right] \frac{n_{a}}{n_{e}}
$$


where $d$ is the distance between two adjacent laser spots measured on the CCD camera of the sensor, $d_{0}$ is the initial distance between the laser spots, $\alpha$ is the angle of reflection of the laser beams, $L$ is the distance between the electrochemical cell and the CCD camera, and $n_{a}$ and $n_{e}$ are the indices of refraction of air and the electrolyte, respectively. In the calculation of the stress, we took $n_{e}=1.42$ for the electrolyte [56] and $n_{a}=1$ for air.

Since the Ge thin-film electrodes were constrained in the plane of the film by the relatively thick substrate, lithium insertion was accommodated entirely by expansion in the thickness direction. As a result, we take the thickness of the film as linear in the state of charge,

$$
h_{f}=h_{f}^{0}(1+\beta s)
$$

Where $h_{f}^{0}$ is the initial thickness of the film, $\beta$ is related to the atomic volumes $(\Omega)$ of Ge and the lithiated phase by $\beta=\left(\Omega_{L i 3.75 G e}-\Omega_{G e}\right) / \Omega_{G e}=2.6$, and $s$ is the state of charge of the electrode, with a value of 0 representing pure silicon and a value of 1 representing the fully lithiated state (assumed to be $\mathrm{Li}_{3.75} \mathrm{Ge}$ with a capacity of $\left.1385 \mathrm{mAh} \mathrm{g}^{-1}\right)$. The state of charge was inferred from the experimental time during the galvanostatic experiments. The value of 2.6 was taken from Liang et al., who found that germanium undergoes a $260 \%$ increase in volume upon full lithiation [49].

\section{Each of the thin-film electrodes was scratched with a diamond scribe to introduce} imperfections off of the sidewalls of the cracks with sizes on the order of the film 
thickness. This technique initiates channel cracks through the thickness of the film so that the fracture analysis by Beuth [57] (analyzed in the Results and Discussion section) is appropriate, as discussed in our previous work [29]. To image cracks in the electrodes, the electrodes were removed from the cell in the glove box, rinsed in dimethyl carbonate, and dried. Next, they were immersed in mineral oil and covered with a glass slide to prevent any air exposure. The samples were then removed from the glove box and examined using an optical microscope.

In order to perform x-ray diffraction (XRD) to analyze the phases of the $\mathrm{Li}_{x} \mathrm{Ge}$ electrodes at different states of charge, we used a three-electrode configuration but with seven working and counter electrodes operating in parallel. See Reference [29] for more details on the custom electrochemical cell with multiple electrodes. The initial thickness of the Ge electrodes was $100 \mathrm{~nm}$. The seven electrodes were lithiated simultaneously at a constant current density of $12.6 \mu \mathrm{A} \mathrm{cm} \mathrm{cm}^{-2}$ (i.e., a C/16 rate assuming a capacity of $1384 \mathrm{mAh} \mathrm{g}^{-1}$ ), three of which were disconnected one by one at various cut-off potentials of $300 \mathrm{mV}, 130 \mathrm{mV}$, and $50 \mathrm{mV}$ to reach different states of charge. The remaining four electrodes were further lithiated to a cut-off potential of $50 \mathrm{mV}$ and then delithiated at the same current density $\left(12.6 \mu \mathrm{A} \mathrm{cm}{ }^{-2}\right)$. These electrodes were disconnected one by one from the cell at various potentials $(380 \mathrm{mV}, 460 \mathrm{mV}, 680 \mathrm{mV}$, $2000 \mathrm{mV}$ ), such that they were only partially delithiated.

The diffraction patterns of these samples were measured using $\mathrm{Cu} \mathrm{K}_{\alpha}$ radiation in a D2 Phaser (Bruker). The electrodes were sealed under an Ar atmosphere in an airtight polyethylene sample holder from Bruker; the XRD experiments were done on the samples in this holder without exposure to air. All XRD measurements were 
performed at room temperature at a rate of five seconds per step and a step size of $0.02^{\circ}$.

Nanoindentation experiments were employed to measure the elastic modulus of the as-deposited Ge films. Tip calibrations were executed using fused silica as a reference material, and machine compliances were subtracted out using a standard approach. The experiments were performed using the same deposition conditions as outlined above on $900 \mathrm{~nm}$ as-deposited Ge films on glass slides with $10 \mathrm{~nm}$ Ti adhesion layers. Indentations were made with an iNano nanoindenter (Nanomechanics Inc., Oak Ridge, TN) equipped with a Berkovich tip using established techniques $[58,59]$. The elastic modulus was determined from contact stiffness measurements obtained for indentations at a depth of $90 \mathrm{~nm}(10 \%$ of the film thickness).

\section{Results and Discussion}

Figure 1 shows the responses of the potential and stress during galvanostatic lithiation and delithiation of Ge electrodes with various thicknesses. During lithiation, the voltage in Figure 1a gradually decreases as the state of charge increases, and the opposite occurs during delithiation. These gradually sloping voltage profiles suggest a single-phase reaction, which may occur due to the slow charging rate $(C / 16)$ used in the experiments.

To further investigate this point, Figure 2 shows XRD patterns of lithiated Ge at various potentials versus $\mathrm{Li} / \mathrm{Li}^{+}$, both during lithiation and delithiation. The patterns at $300 \mathrm{mV}, 130 \mathrm{mV}$, and $50 \mathrm{mV}$ correspond to lithiation, while $380 \mathrm{mV}, 460 \mathrm{mV}, 690 \mathrm{mV}$, 
and $2000 \mathrm{mV}$ correspond to delithiation. The peaks at approximately $43^{\circ}$ and $50^{\circ}$ are from the Cu current collector, while the peak at $38^{\circ}$ is attributed to the Ti adhesion layer. No other peaks can be observed in the as-deposited Ge sample, indicating that the sputter-deposited Ge film is amorphous. During lithiation, there is no significant change in the peaks all the way down to the cutoff voltage of $50 \mathrm{mV}$. In addition, no changes in the peaks are detected during delithiation, indicating that the Li-Ge compound in our experiments remained amorphous during the lithiation cycle. In contrast, several researchers have reported that lithiation of Ge electrodes involves a two-step phase transformation: a-Ge (or c-Ge) $\rightarrow$ a-Li $\mathrm{C}_{x} \mathrm{Ge} \rightarrow \mathrm{c}-\mathrm{Li}_{15} \mathrm{Ge}_{4}[49,52]$. For example, Liu and Liang have observed the microstructural evolution of c-Ge nanowires/particles during lithiation by in-situ TEM $[48,29]$. They reported that their initial c-Ge was gradually converted to a- $\mathrm{Li}_{\mathrm{x}} \mathrm{Ge}$ in a core-shell geometry, followed by conversion of the a-Lix $\mathrm{Ge}$ to c-Li ${ }_{15} \mathrm{Ge}_{4}$. In addition, Baggetto and Notten performed XRD measurements on evaporated and sputtered a-Ge electrodes to observe the phase transformations during lithiation and delithiation [52]. They suggested that a phase transformation of a-Lix $\mathrm{Ge}$ to $\mathrm{C}-\mathrm{Li}_{15} \mathrm{Ge}_{4}$ takes place between $130 \mathrm{mV}$ and $20 \mathrm{mV}$ [52]. We surmise that the difference between our experiments and others may be due to the Ge deposition conditions, the relatively slow charging rates, and/or the relatively large lower cutoff potential used in our experiments $(50 \mathrm{mV})$. In any event, the $\mathrm{XRD}$ data suggests that in our experiments $\mathrm{Li}_{x} \mathrm{Ge}$ remained amorphous throughout electrochemical cycling.

As lithium is first inserted, the compressive stress in the electrodes rises rapidly until it reaches a value of $800-900 \mathrm{MPa}$ (Figure 1b). At that point, the $\mathrm{Li}_{x} \mathrm{Ge}$ yields and the stress reduces upon further lithium insertion. The stress in this regime corresponds 
to the flow stress of lithiated $\mathrm{Ge}$. The data in Figure $1 \mathrm{~b}$ show that the reduction in flow stress with increasing lithium content is quite substantial - for instance, the flow stress of $\mathrm{Li}_{3.75} \mathrm{Ge}$ is approximately $270 \mathrm{MPa}$. Upon delithiation, there is an initial elastic regime, during which the stress rapidly increases as lithium is extracted. This regime is followed by yield in tension and a gradual increase in flow stress with reducing lithium concentration. For the $320 \mathrm{~nm}$ and $1160 \mathrm{~nm}$ films, there is a peak in the flow stress, which is followed by an apparent drop in stress with further delithiation.

The observation of plastic deformation in the $\mathrm{Li}_{x} \mathrm{Ge}$ electrodes is critical, because plastic flow limits the stresses that build up during delithiation. In particular, the energy release rate, $G$, i.e., the driving force for fracture, scales as

$$
G \mu \frac{{ }_{f}^{2} h_{f}}{E_{f}},
$$

where $\sigma_{f}$ is the stress in the film, $h_{f}$ is the thickness of the film, and $E_{f}$ is the elastic modulus of the film [32]. If the deformation were entirely elastic, the stress in the film would be $\sigma_{f} \sim E_{f} \varepsilon_{f}$. Due to the enormous strains $\varepsilon_{f}$ associated with lithium insertion, a likewise elevated stress and crack driving force would develop in the film. However, due to plastic deformation of the $\mathrm{a}-\mathrm{Li}_{x} \mathrm{Ge}$ electrode, the stresses in the film are instead limited by the yield stress, thereby drastically reducing the crack driving force. In other words, materials that readily deform plastically during a lithiation cycle, flow rather than fracture. With this point in mind, Figure 3 shows a comparison of the stresses developed during galvanostatic $(\mathrm{C} / 16)$ lithiation and delithiation of $\mathrm{Si}$ [29] and $\mathrm{Ge}$ electrodes. The Ge electrodes flow at a lower stress than their Si counterparts. As 
shown by Equation 4, even a modest reduction in the yield stress has a big (squared dependence) impact on the crack driving force. Thus, the relatively small flow stress observed for lithiated $\mathrm{Ge}$ indicates a key advantage in terms of its resistance to fracture.

The elastic modulus of $\mathrm{Li}_{x} \mathrm{Ge}$ can be determined by the change in the stress in the electrode during the elastic unloading (and re-loading) segments of the lithiation cycles, as was done in previous studies $[29,35,39]$. The elastic modulus of the $\mathrm{Li}_{x} \mathrm{Ge}$ film, $E_{f}$, is given by

$$
E_{f}=-3\left(1-v_{f}\right) \frac{1+\beta s}{\beta} \frac{\Delta \sigma}{\Delta s},
$$

where $v_{f}$ is Poisson's ratio of the film and $\Delta \sigma / \Delta s$ is the increment in stress over a sufficiently small change in state of charge [29]. For the calculations, we take $v_{f}=0.28$, the value for pure $\mathrm{Ge}$ [55]. It is unlikely that this value changes dramatically with lithium concentration, as evidenced in a similar study on $\mathrm{Li}_{x} \mathrm{Si}$ [44]. The values are in the range of $E_{f}=22-36 \mathrm{GPa}$ for our samples, as shown in Table 1. We also performed nanoindentation measurements on the as-deposited a-Ge films, finding a value of $E_{f}=95 \pm 10 \mathrm{GPa}$, which is similar to those reported in literature for a-Ge $[60,61]$. As the values for lithiated germanium are much smaller than that of pure $\mathrm{Ge}$, it is evident that even a small amount of lithium insertion into a-Ge results in a large change in elastic modulus. Further increases in lithium concentration seem to lead to a more gradual change of the elastic modulus. 
We have also investigated fracture of $\mathrm{Li}_{x} G e$ electrodes under these lithiation conditions. In particular, it was found that the $1160 \mathrm{~nm}$ film completely pulverized and delaminated from its substrate after one lithiation/delithiation cycle, which is consistent with the reduction in stress to approximately zero at $x \approx 1.3$ (Figure 1). The other two films did not show such obvious pulverization or reduction to zero stress. However, observation in an optical microscope indicated that the $320 \mathrm{~nm}$ film also fractured after one cycle, while the $100 \mathrm{~nm}$ film did not, as shown in Figure 4.

As discussed extensively in our previous work, when a dense set of cracks forms in a film, the curvature of the substrate decreases correspondingly, i.e., the cracks make the stress in the film appear more compressive than it actually is [29]. We believe that fracture is responsible for the peaks evident in Figure $1 \mathrm{~b}$ for the 320 and $1160 \mathrm{~nm}$ films. In other words, the peaks in the stress correspond to the critical conditions for the onset of fracture. The validity of this approach for determining the fracture energy of a thin film has been discussed in our previous work [29]. Fracture of these films initially occurs in the form of long channel cracks that extend through the thickness of the film. For such cracks, the fracture energy of the films can be determined with an analysis from Reference [57]: the energy release rate for channeling cracks in an elastic thin film bonded to an elastic substrate is given by

$$
G=g(\alpha, \beta) \frac{\sigma_{f}^{2} h_{f}}{\bar{E}_{f}}
$$


where $\bar{E}_{f}=E_{f}\left(1-v_{f}^{2}\right)$ is the plane-strain modulus of the film and $g(\alpha, \beta)$ is a dimensionless parameter that is a function of the Dundurs parameters, $\alpha$ and $\beta$, defined by

$$
\alpha=\frac{\bar{E}_{f}-\bar{E}_{s}}{\bar{E}_{f}+\bar{E}_{s}}, \quad \beta=\frac{\mu_{f}\left(1-2 v_{s}\right)-\mu_{s}\left(1-2 v_{f}\right)}{2 \mu_{f}\left(1-v_{s}\right)+2 \mu_{s}\left(1-v_{f}\right)} .
$$

In these expressions, the $\bar{E}_{i}=E_{i} /\left(1-v_{i}^{2}\right)$ represent the respective plane-strain moduli and the $\mu_{i}=E_{i} /\left[2\left(1+v_{i}\right)\right]$ represent the shear moduli [57]. To determine the fracture energy, we calculate the energy release rate at the critical conditions for fracture, i.e., at the peaks in the stress for the 320 and $1160 \mathrm{~nm}$ films. The stress at the critical lithium concentration is taken from Figure 1b, the corresponding film thickness is calculated using Equation 3, and the elastic modulus is taken from Table 1. The dimensionless parameter $g(\alpha, \beta)$ is interpolated from Reference [57], yielding $g(\alpha, \beta) \approx 0.94$ for the $320 \mathrm{~nm}$ film and $g(\alpha, \beta) \approx 0.91$ for the $1160 \mathrm{~nm}$ film. The corresponding fracture energies are then $\Gamma=8.0 \mathrm{~J} \mathrm{~m}^{-2}$ for $\mathrm{a}-\mathrm{Li}_{0.3} \mathrm{Ge}$ and $\Gamma=5.6 \mathrm{~J} \mathrm{~m}^{-2}$ for $\mathrm{a}-\mathrm{Li}_{1.6} \mathrm{Ge}$.

These values are typical for brittle fracture and are in fact similar to the fracture toughness of pure Ge. Indeed, the critical stress intensity factor of single-crystalline Ge is $\mathrm{K}_{\mathrm{IC}}=1.004 \mathrm{MPa} \cdot \mathrm{m}^{1 / 2}$ for the (110) fracture plane. Using a Poisson's ratio of 0.28 and a stiffness in the [110] direction of $138 \mathrm{GPa}$ in Irwin's equation yields $\Gamma=K_{l C}^{2}\left(1-v^{2}\right) / E=6.7 \mathrm{~J} \mathrm{~m}^{-2}[62]$. However, unlike pure $\mathrm{Ge}, \mathrm{a}-\mathrm{Li} \mathrm{i}_{\mathrm{x}} \mathrm{Ge}$ is capable of extensive plastic flow during electrochemical cycling, as evidenced in Figure 1b. In other words, a-Li $\mathrm{i}_{x} \mathrm{Ge}$ has a peculiar combination of properties $-\mathrm{a}-\mathrm{Li}_{\mathrm{x}} \mathrm{Ge}$ has the ability to flow 
plastically, but undergoes brittle fracture. This combination of properties was also found in a-Li $\mathrm{i}_{x} \mathrm{Si}$ in our previous work [63]. These seemingly paradoxical characteristics of lithiated silicon were reconciled by the observation that plastic flow in $\mathrm{a}-\mathrm{Li} \mathrm{i}_{\mathrm{S}} \mathrm{Si}$ is rate sensitive [63]: plastic flow at larger strain rates (such as those in the vicinity of a crack tip when the crack propagates) requires larger stresses in a- $\mathrm{Li}_{x} \mathrm{Si}$. As a result, the strains associated with fracture are primarily elastic, resulting in brittle fracture. It is likely that a similar mechanism is responsible for the behavior of a- $\mathrm{Li}_{x} \mathrm{Ge}$, but further studies similar to that in Reference [63] are necessary to confirm this notion.

The fracture energy of a-Lix $\mathrm{Ge}$ is similar to the fracture energy of a-Li $\mathrm{i}_{x} \mathrm{Si}$ measured in our previous work $-\Gamma=8.0 \mathrm{~J} \mathrm{~m}^{-2}$ for a- $\mathrm{Li}_{0.3} \mathrm{Ge}$ and $\Gamma=5.6 \mathrm{~J} \mathrm{~m}^{-2}$ for a$\mathrm{Li}_{1.6} \mathrm{Ge}$, as compared to $\Gamma=8.5 \mathrm{~J} \mathrm{~m}^{-2}$ for a- $\mathrm{Li}_{0.7} \mathrm{Si}$ and $\Gamma=5.4-6.9 \mathrm{~J} \mathrm{~m}^{-2}$ for a-Li $\mathrm{Li}_{2.8} \mathrm{Si}$ [29]. Thus, it may seem that Ge and Si electrodes are comparable in terms of resistance to fracture in electrochemical applications. However, as discussed above and shown in Figure 3, the flow stress of a-Lix $\mathrm{Ge}$ is substantially less than that of a-Lix $\mathrm{Si}$. Consequently, the crack driving force during electrochemical cycling is significantly lower for a-Lix $\mathrm{Ge}$, as evident from Equation 4. As an example, the flow stress in the fully lithiated state is $\sigma_{Y}=411 \mathrm{MPa}$ for a- $\mathrm{Li}_{3.75} \mathrm{Si}$ and $\sigma_{Y}=274 \mathrm{MPa}$ for a- $\mathrm{Li}_{3.75} \mathrm{Ge}$ (both defined in compression here to enable a fair comparison). Thus, the difference in flow stresses alone results in lithiated silicon having 2.3 times the driving force for fracture of lithiated germanium, ceteris paribus. This difference in the crack driving force is consistent with recent observations of "tough" Ge nanoparticles [49, 50]. In particular, Lee et al. [50] found a critical diameter for lithiation-induced fracture of $<111>\mathrm{c}-\mathrm{Ge}$ micro-pillars of $\sim 1.2 \mu \mathrm{m}$, which was much larger than the corresponding critical 
diameter of $\sim 300 \mathrm{~nm}$ that they found in $<111>$ c-Si micro-pillars [25]. The authors attributed this difference to the highly anisotropic deformation found during lithiation of c-Si micro-pillars, as compared to the nearly isotropic deformation found during lithiation of c-Ge micro-pillars. From their modeling, the anisotropic deformation in Si was found to lead to stress concentrations that are on the order of two to three times larger than those found during the nearly isotropic lithiation of Ge (assuming the same flow stress) [50]. Our results demonstrate clearly that the relative "toughness" of c-Ge electrodes is not due to an enhanced fracture toughness of $\mathrm{Li}_{x} \mathrm{Ge}$ over $\mathrm{Li}_{x} \mathrm{Si}$, but is instead due to the relatively low flow stress of $\mathrm{Li}_{\mathrm{x}} \mathrm{Ge}$, in addition to the fairly isotropic deformation observed during electrochemical cycling $[49,50]$.

\section{Conclusions}

We have performed in-situ measurements of the stresses, stiffness, and fracture energy of a-Lix $\mathrm{Ge}$ thin-film electrodes during electrochemical cycling. The a- $\mathrm{Li}_{x} \mathrm{Ge}$ electrodes were observed to flow plastically at stresses smaller than those found in a$\mathrm{Li}_{x} \mathrm{Si}$ electrodes, resulting in a comparatively small crack driving force in a-Lix $\mathrm{Ge}$. While $100 \mathrm{~nm}$ films of Ge survive a cycle of lithiation and delithiation, thicker films fracture. The fracture energies were determined from the critical conditions for crack formation to be $\Gamma=8.0 \mathrm{~J} \mathrm{~m}^{-2}$ for a-Li ${ }_{0.3} \mathrm{Ge}$ and $\Gamma=5.6 \mathrm{~J} \mathrm{~m}^{-2}$ for a-Li ${ }_{1.6} \mathrm{Ge}$, indicating brittle fracture similar to that of pure Ge. Thus, a- $\mathrm{Li}_{x} \mathrm{Ge}$ exhibits the peculiar ability to flow plastically, but fracture in a brittle manner. Overall, these measurements provide quantitative guidelines for the practical design of germanium electrodes that avoid fracture. Generally speaking, Ge electrodes are more resilient to fracture than their $\mathrm{Si}$ 
counterparts, thereby rendering Ge a viable candidate as anode material for lithium-ion batteries.

\section{Acknowledgments}

This work was supported by the National Science Foundation through a grant on Lithium-ion Batteries (CMMI-1031161). It was performed in part at the Center for Nanoscale Systems, a member of the National Nanotechnology Infrastructure Network, which is supported by the National Science Foundation under NSF Award No. ECS0335765, and at the Harvard University Materials Research Science and Engineering Center, which is supported by the National Science Foundation under Award No. DMR1420570. M.P. acknowledges support by the National Science Foundation Graduate Research Fellowship Program. Work at Seoul National University was supported by a grant from the Fundamental R\&D Program for Technology of World Premier Materials funded by the Ministry of Knowledge Economy, Republic of Korea (10037919). 


\section{References}

[1] M. Armand, J.M. Tarascon, Nature 451 (2008) 652-657.

[2] J.M. Tarascon, M. Armand, Nature 414 (2001) 359-367.

[3] R. Marom, S.F. Amalraj, N. Leifer, D. Jacob, D. Aurbach, J. Mater. Chem. 21 99389954.

[4] M.S. Whittingham, MRS Bull. 33 (2008) 411-419.

[5] U. Kasavajjula, C. Wang, A.J. Appleby, J. Power Sources 163 (2007) 1003-1039.

[6] S.-B. Son, J.E. Trevey, H. Roh, S.-H. Kim, K.-B. Kim, J.S. Cho, J.-T. Moon, C.M.

DeLuca, K.K. Maute, M.L. Dunn, H.N. Han, K.H. Oh, S.-H. Lee, Adv. Energy Mater. 1 (2011) 1199-1204.

[7] M.N. Obrovac, L. Christensen, Electrochem. Solid State Lett. 7 (2004) A93-A96.

[8] J.R. Dahn, T. Zheng, Y. Liu, J.S. Xue, Science 270 (1995) 590-593.

[9] M. Pharr, K. Zhao, X. Wang, Z. Suo, J.J. Vlassak, Nano Lett. 12 (2012) 5039-5047. [10] M.J. Chon, V.A. Sethuraman, A. McCormick, V. Srinivasan, P.R. Guduru, Phys. Rev. Lett. 107 (2011) 045503.

[11] R. Deshpande, M. Verbrugge, Y.T. Cheng, J. Wang, P. Liu, J. Electrochem. Soc. 159 (2012) A1730-A1738.

[12] S.P.V. Nadimpalli, V.A. Sethuraman, S. Dalavi, B. Lucht, M.J. Chon, V.B. Shenoy, P.R. Guduru, J. Power Sources 215 (2012) 145-151.

[13] L.Y. Beaulieu, K.W. Eberman, R.L. Turner, L.J. Krause, J.R. Dahn, Electrochem. Solid State Lett. 4 (2001) A137-A140.

[14] C.K. Chan, H. Peng, G. Liu, K. Mcllwrath, X.F. Zhang, R.A. Huggins, Y. Cui, Nature Nanotechnol. 3 (2008) 31-35.

[15] H. Haftbaradaran, X. Xiao, M.W. Verbrugge, H. Gao, J. Power Sources 206 (2012) 357-366.

[16] H. Zhang, P.V. Braun, Nano Lett. 12 (2012) 2778-2783.

[17] L. Baggetto, D. Danilov, P.H.L. Notten, Adv. Mater. 23 (2011) 1563-1566.

[18] T. Takamura, S. Ohara, M. Uehara, J. Suzuki, K. Sekine, J. Power Sources 129 (2004) 96-100.

[19] K. Peng, J. Jie, W. Zhang, S.-T. Lee, Appl. Phys. Lett. 93 (2008) 033105.

[20] C. Yu, X. Li, T. Ma, J. Rong, R. Zhang, J. Shaffer, Y. An, Q. Liu, B. Wei, H. Jiang, Adv. Energy Mater. 2 (2012) 68-73.

[21] Y. Yao, M.T. McDowell, I. Ryu, H. Wu, N. Liu, L. Hu, W.D. Nix, Y. Cui, Nano Lett. 11 (2011) 2949-2954.

[22] H. Wu, G. Chan, J.W. Choi, I. Ryu, Y. Yao, M.T. McDowell, S.W. Lee, A. Jackson, Y. Yang, L. Hu, Y. Cui, Nature Nanotechnol. 7 (2012) 309-314.

[23] S.K. Soni, B.W. Sheldon, X. Xiao, M.W. Verbrugge, D. Ahn, H. Haftbaradaran, H. Gao, J. Electrochem. Soc. 159 (2012) A38-A43.

[24] S.K. Soni, B.W. Sheldon, X. Xiao, A. Tokranov, Scripta Mater. 64 (2011) 307-310.

[25] S.W. Lee, M.T. McDowell, L.A. Berla, W.D. Nix, Y. Cui, Proc. Natl. Acad. Sci. 109 (2012) 4080-4085.

[26] S.W. Lee, M.T. McDowell, J.W. Choi, Y. Cui, Nano Lett. 11 (2011) 3034-3039.

[27] G. Bucci, S.P.V. Nadimpalli, V.A. Sethuraman, A.F. Bower, P.R. Guduru, J. Mech. Phys. Solids 62 (2014) 276-294.

[28] V.A. Sethuraman, M.J. Chon, M. Shimshak, V. Srinivasan, P.R. Guduru, J. Power Sources 195 (2010) 5062-5066. 
[29] M. Pharr, Z. Suo, J.J. Vlassak, Nano Lett. 13 (2013) 5570-5577.

[30] K. Zhao, W.L. Wang, J. Gregoire, M. Pharr, Z. Suo, J.J. Vlassak, E. Kaxiras, Nano Lett. 11 (2011) 2962-2967.

[31] K. Zhao, M. Pharr, Q. Wan, W.L. Wang, E. Kaxiras, J.J. Vlassak, Z. Suo, J. Electrochem. Soc. 159 (2012) A238-A243.

[32] K. Zhao, M. Pharr, J.J. Vlassak, Z. Suo, J. Appl. Phys. 109 (2011) 016110.

[33] K. Zhao, M. Pharr, S. Cai, J.J. Vlassak, Z. Suo, J. Am. Ceram. Soc. 94 (2011) S226-S235.

[34] K. Zhao, G.A. Tritsaris, M. Pharr, W.L. Wang, O. Okeke, Z. Suo, J.J. Vlassak, E. Kaxiras, Nano Lett. 12 (2012) 4397-4403.

[35] V.A. Sethuraman, M.J. Chon, M. Shimshak, N. Van Winkle, P.R. Guduru, Electrochem. Commun. 12 (2010) 1614-1617.

[36] B.W. Sheldon, S.K. Soni, X. Xiao, Y. Qi, Electrochem. Solid State Lett. 15 (2012) A9-A11.

[37] S.T. Boles, C.V. Thompson, O. Kraft, R. Moenig, Appl. Phys. Lett. 103 (2013) 263906.

[38] A.F. Bower, P.R. Guduru, V.A. Sethuraman, J. Mech. Phys. Solids 59 (2011) 804828.

[39] Y.S. Choi, M. Pharr, K.H. Oh, J.J. Vlassak, J. Power Sources 294 159-166.

[40] Y. He, X. Yu, G. Li, R. Wang, H. Li, Y. Wang, H. Gao, X. Huang, J. Power Sources 216 (2012) 131-138.

[41] B. Hertzberg, A. Alexeev, G. Yushin, J. Am. Chem. Soc. 132 (2010) 8548-8549.

[42] B. Hertzberg, J. Benson, G. Yushin, Electrochem. Commun. 13 (2011) 818-821.

[43] S. Huang, T. Zhu, J. Power Sources 196 (2011) 3664-3668.

[44] V.B. Shenoy, P. Johari, Y. Qi, J. Power Sources 195 (2010) 6825-6830.

[45] S.K. Soni, B.W. Sheldon, X. Xiao, A.F. Bower, M.W. Verbrugge, J. Electrochem. Soc. 159 (2012) A1520-A1527.

[46] W.J. Zhang, J. Power Sources 196 (2011) 13-24.

[47] J. Graetz, C.C. Ahn, R. Yazami, B. Fultz, J. Electrochem. Soc. 151 (2004) A698A702.

[48] X.H. Liu, S. Huang, S.T. Picraux, J. Li, T. Zhu, J.Y. Huang, Nano Lett. 11 (2011) 3991-3997.

[49] W. Liang, H. Yang, F. Fan, Y. Liu, X.H. Liu, J.Y. Huang, T. Zhu, S. Zhang, ACS Nano 7 (2013) 3427-3433.

[50] S.W. Lee, I. Ryu, W.D. Nix, Y. Cui, Extreme Mech. Lett. 2 (2015) 15-19.

[51] D. Larcher, S. Beattie, M. Morcrette, K. Edstrom, J.-C. Jumas, J.-M. Tarascon, J. Mater. Chem. 17 (2007) 3759-3772.

[52] L. Baggetto, P.H.L. Notten, J. Electrochem. Soc. 156 (2009) A169-A175.

[53] G.G. Stoney, Proc. R. Soc. Lond. Ser. A 82 (1909) 172-175.

[54] W.D. Nix, Metall. Trans. A 20 (1989) 2217-2245.

[55] Physical properties of clear soda lime float glass provided by manufacturer, Abrisa Technologies, Santa Paula, CA.

[56] M.A. McArthur, S. Trussler, J.R. Dahn, J. Electrochem. Soc. 159 (2012)

A198-A207.

[57] J.L. Beuth, Int. J. Solids Struct. 29 (1992) 1657-1675.

[58] W.C. Oliver, G.M. Pharr, J. Mater. Res. 7 (1992) 1564-1583. 
[59] W.C. Oliver, G.M. Pharr, J. Mater. Res. 19 (2004) 3-20.

[60] L. Guttman, Solid State Commun. 24 (1977) 211-212.

[61] A. Witvrouw, F. Spaepen, J. Appl. Phys. 74 (1993) 7154-7161.

[62] Physical properties of germanium provided by manufacturer, Umicore Optical Materials, Quapaw, Oklahoma.

[63] M. Pharr, Z. Suo, J.J. Vlassak, J. Power Sources, 270 (2014) 569-575. 


\begin{tabular}{|c|c|c|c|}
\hline Thickness & $x$ in $\mathrm{Li}_{x} \mathrm{Ge}$ & $\mathrm{E}(\mathrm{GPa})$ & $\Gamma\left(\mathrm{J} \mathrm{m}^{-2}\right)$ \\
\hline \multirow{4}{*}{$100 \mathrm{~nm}$} & 3.8 & 34 & 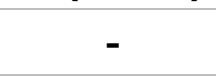 \\
\hline & 0.3 & $23^{*}$ & - \\
\hline & 0.4 & $24^{*}$ & - \\
\hline & 3.8 & $36^{*}$ & - \\
\hline \multirow{3}{*}{$320 \mathrm{~nm}$} & 0.3 & $25^{*}$ & 8.0 \\
\hline & 2.7 & 30 & - \\
\hline & 3.0 & $30^{*}$ & - \\
\hline $1160 \mathrm{~nm}$ & 1.6 & 22 & 5.6 \\
\hline
\end{tabular}

Table 1. Results of experiments to determine mechanical properties of a-Lix $\mathrm{Ge}$ as a function of lithium concentration. The * indicates additional experiments on different samples that are not shown in Figure 1 (for the sake of clarity of that figure). 
Figures
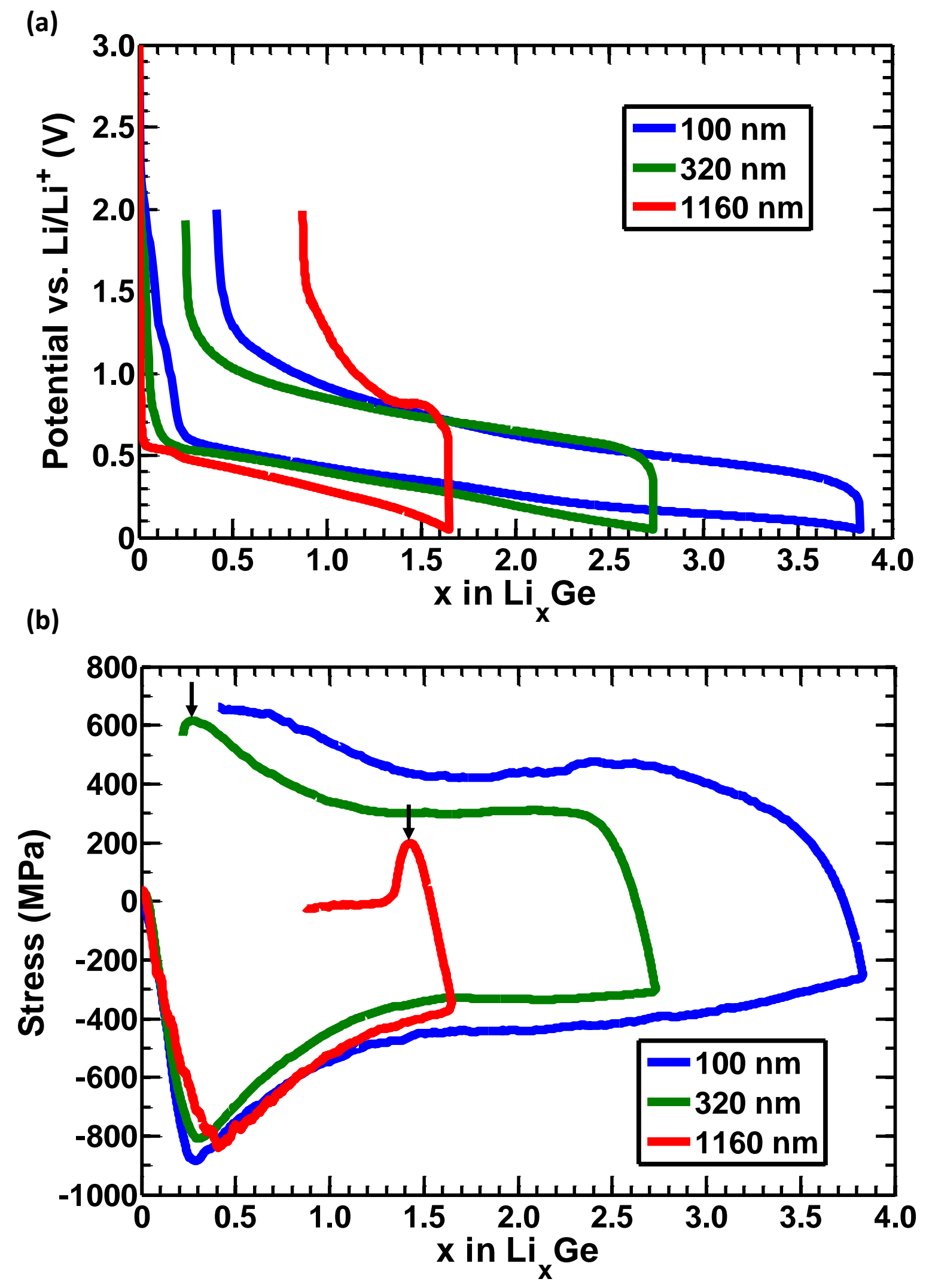
Figure 1. Responses in (a) potential vs. $\mathrm{Li}^{\mathrm{Li}} \mathrm{Li}^{+}$and (b) stress as a function of lithium concentration from galvanostatic tests on a-Ge thin films with various thicknesses. For the thicker films, the black arrows indicate the location of the maximum tensile stress during delithiation, corresponding to fracture of the electrodes. 


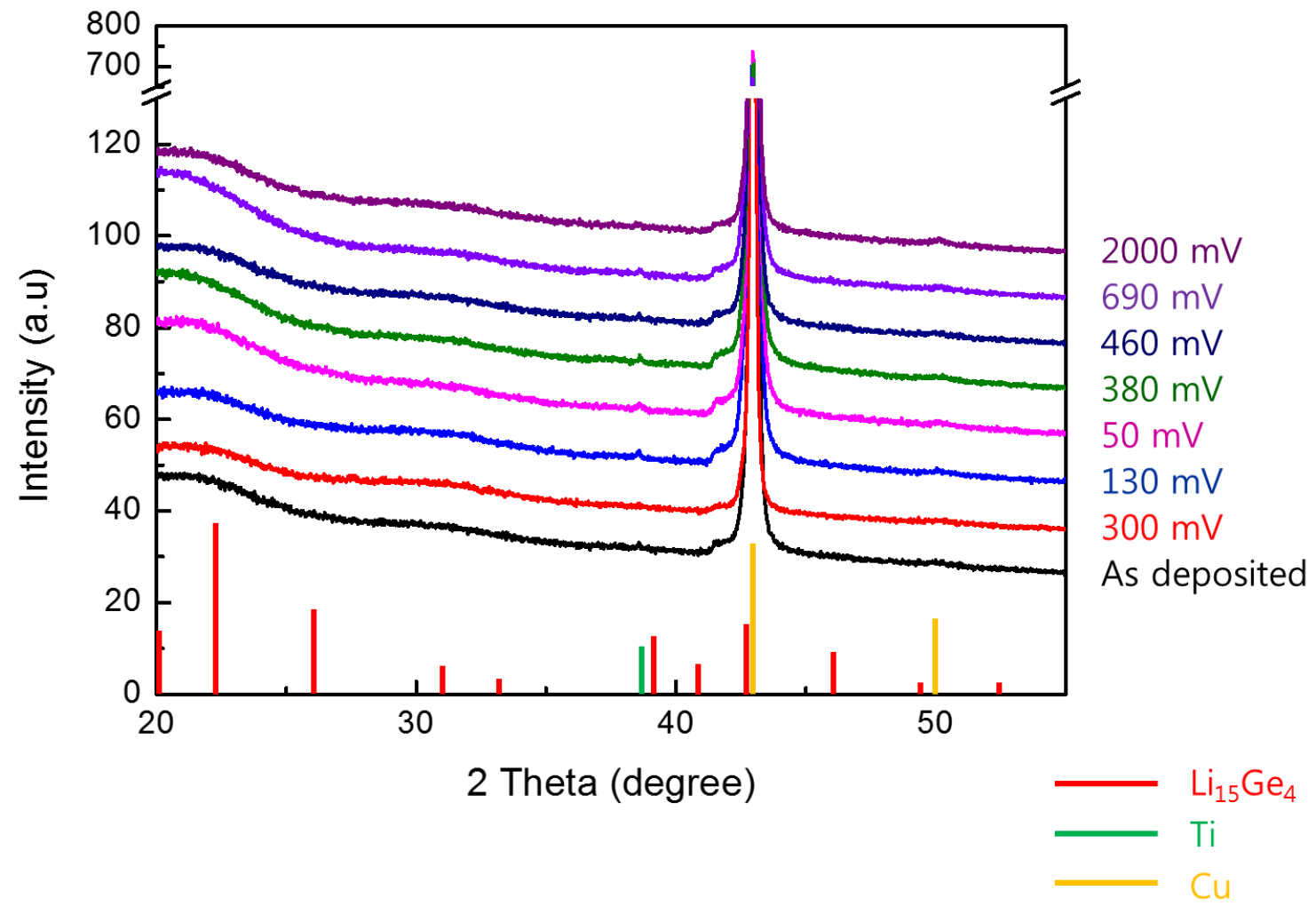

Figure 2. X-ray diffraction data of a $100 \mathrm{~nm}$ film of $\mathrm{Ge}$ at various potentials versus $\mathrm{Li} / \mathrm{Li}^{+}$ during lithiation and delithiation. The various potentials correspond to various concentrations of lithium as shown in Figure 1a. The curves at $300 \mathrm{mV}, 130 \mathrm{mV}$, and 50 $\mathrm{mV}$ correspond to lithiation, while $380 \mathrm{mV}, 460 \mathrm{mV}, 690 \mathrm{mV}$, and $2000 \mathrm{mV}$ correspond to delithiation. The film remains amorphous during the entire cycle. 


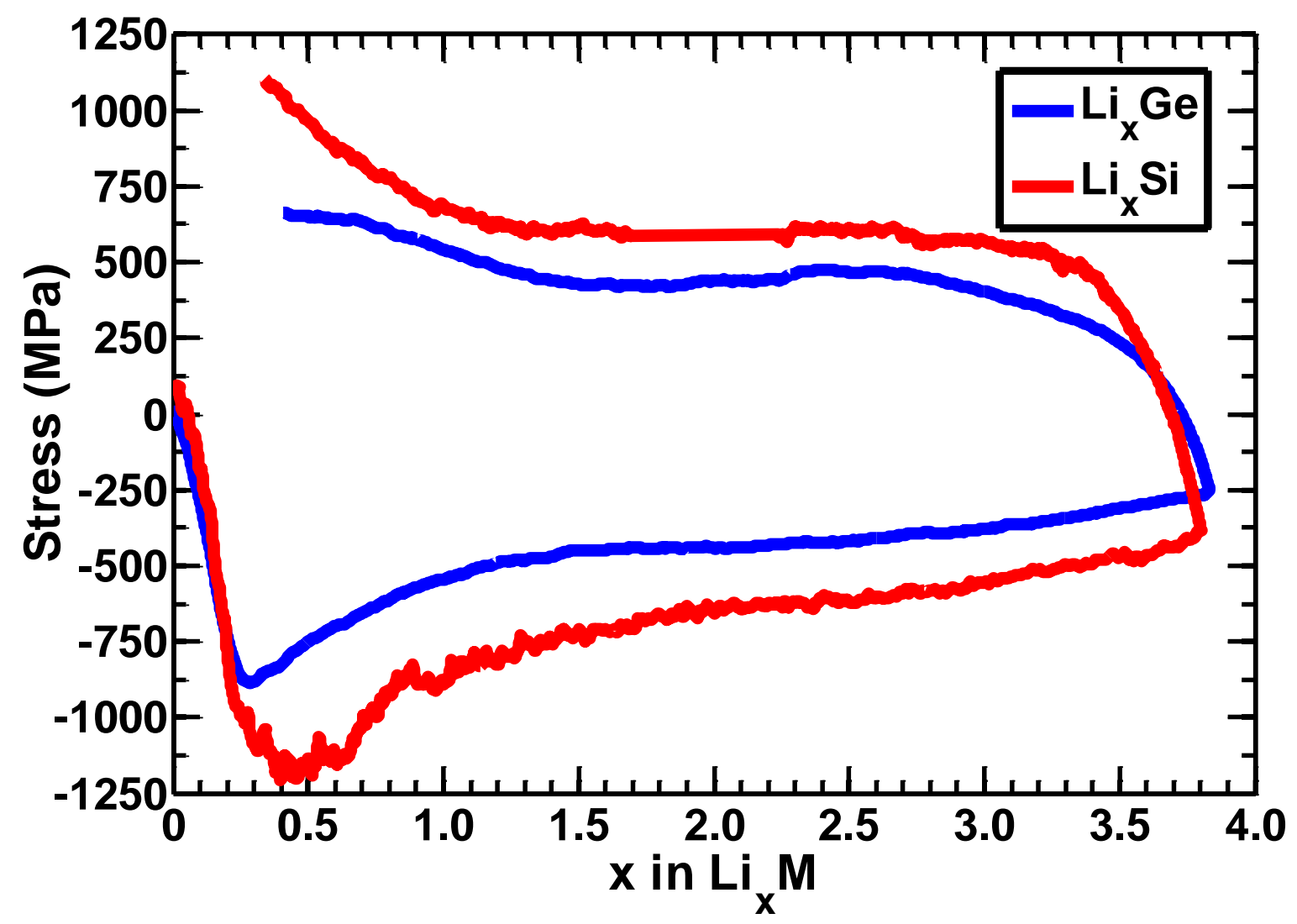

Figure 3. Comparison of the stresses developed during lithiation and delithiation of silicon [29] and germanium thin films. The stresses developed in germanium are smaller than the corresponding stresses in silicon. 

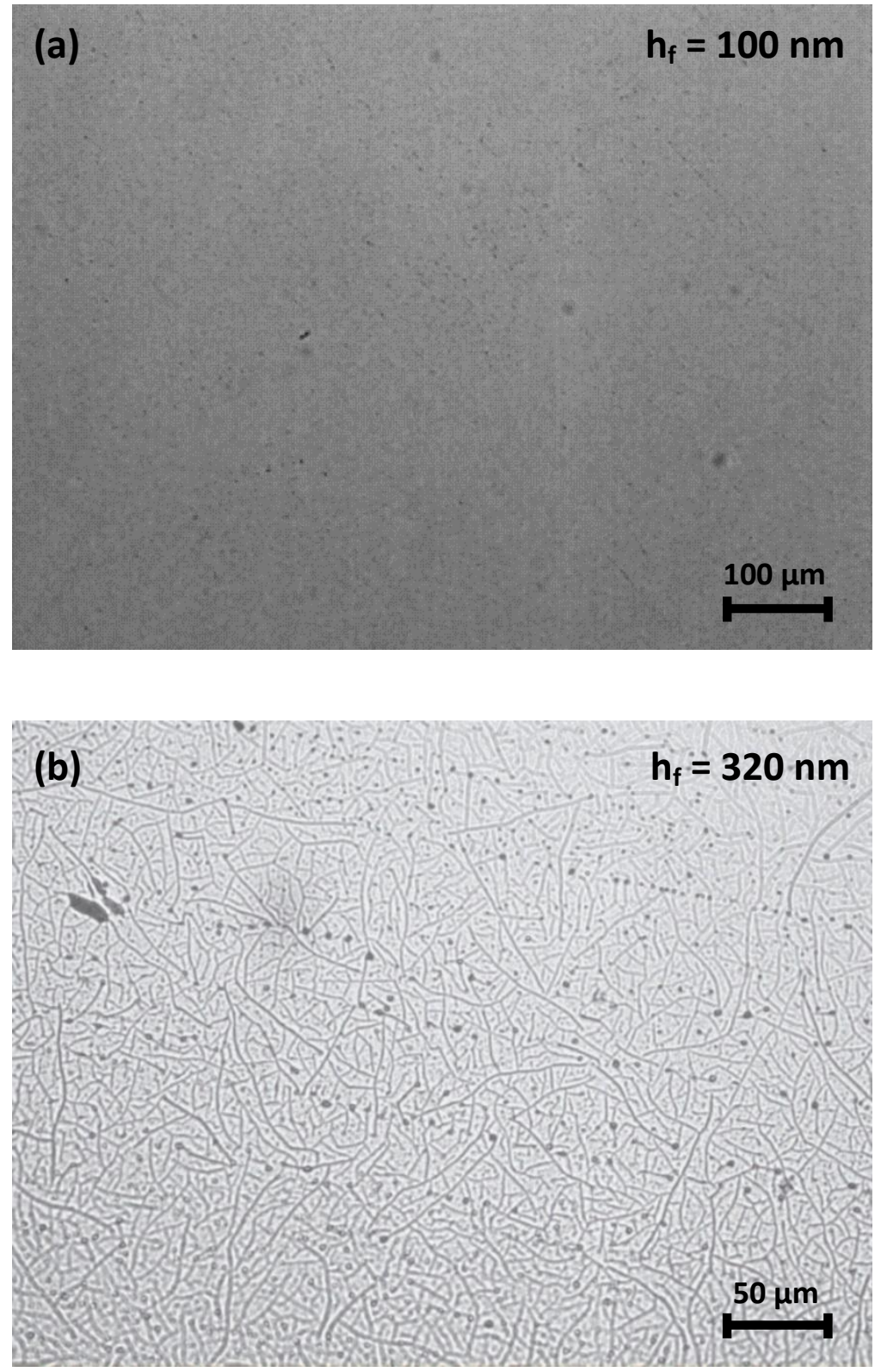

Figure 4. Optical micrographs after a cycle of lithiation / delithiation of two of the electrodes tested in Figure 1 with thicknesses of (a) $100 \mathrm{~nm}$ and (b) $320 \mathrm{~nm}$. 
Figure 1. Responses in (a) potential vs. $\mathrm{Li}^{\mathrm{Li}} \mathrm{i}^{+}$and (b) stress as a function of lithium concentration from galvanostatic tests on a-Ge thin films with various thicknesses. For the thicker films, the black arrows indicate the location of the maximum tensile stress during delithiation, corresponding to fracture of the electrodes.

Figure 2. X-ray diffraction data of a $100 \mathrm{~nm}$ film of $\mathrm{Ge}$ at various potentials versus $\mathrm{Li} / \mathrm{Li}^{+}$ during lithiation and delithiation. The various potentials correspond to various concentrations of lithium as shown in Figure 1a. The curves at $300 \mathrm{mV}, 130 \mathrm{mV}$, and 50 $\mathrm{mV}$ correspond to lithiation, while $380 \mathrm{mV}, 460 \mathrm{mV}, 690 \mathrm{mV}$, and $2000 \mathrm{mV}$ correspond to delithiation. The film remains amorphous during the entire cycle.

Figure 3. Comparison of the stresses developed during lithiation and delithiation ofsilicon [29] and germanium thin films. The stresses developed in germanium are smaller than the corresponding stresses in silicon.

Figure 4. Optical micrographs after a cycle of lithiation / delithiation of two of the electrodes tested in Figure 1 with thicknesses of (a) $100 \mathrm{~nm}$ and (b) $320 \mathrm{~nm}$. 


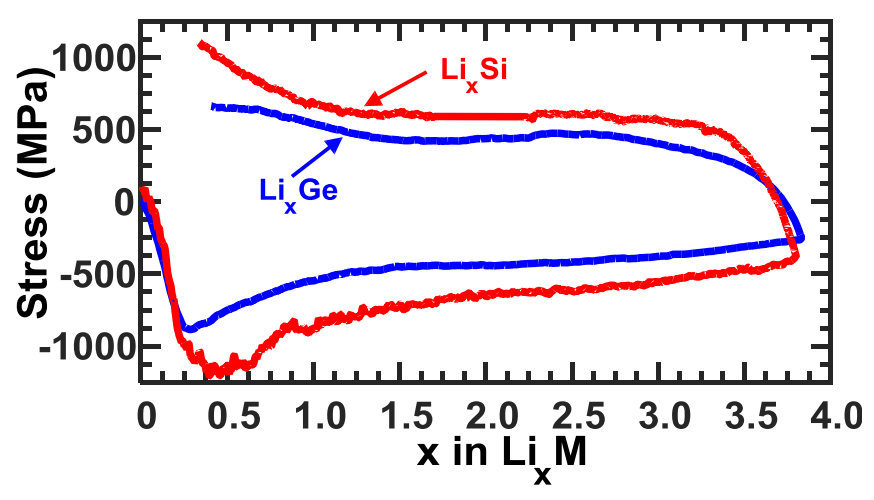

Graphical Abstract in $\mathrm{Li}_{x} \mathrm{M}$ 